\title{
Borderline pulmonary hypertension is associated with exercise intolerance and increased risk for acute exacerbation in patients with interstitial lung disease
}

Kenji Nemoto*, Shuji Oh-ishi, Tatsuya Akiyama, Yuki Yabuuchi, Hitomi Goto, Mizu Nonaka, Yuika Sasatani, Hiroaki Tachi, Naoki Arai, Hiroaki Ishikawa, Kentaro Hyodo, Isano Hase, Yukiko Miura, Takio Takaku, Kenji Hayashihara and Takefumi Saito

\begin{abstract}
Background: Pulmonary hypertension $(\mathrm{PH})$ is traditionally defined as a resting mean pulmonary artery pressure (mPAP) of $\geq 25 \mathrm{mmHg}$, while mPAP in the range of 21 to $24 \mathrm{mmHg}$ is recognized as "borderline PH." Interstitial lung disease (ILD) is complicated by the development of $\mathrm{PH}$, which is known to be linked with exercise intolerance and a poor prognosis. Even though it has recently been recommended that $\mathrm{PH}$ is redefined as a mPAP of $>20 \mathrm{mmHg}$, little is known about the clinical significance of borderline PH in ILD. We evaluated whether borderline PH has an impact on the exercise capacity, risk of acute exacerbation (AE), and mortality in patients with ILD.

Methods: A total of 80 patients with ILD who underwent right heart catheterization (RHC) between November 2013 and October 2016 were included. The patients were divided into 3 groups according to the MPAP values: $\mathrm{mPAP} \leq 20 \mathrm{mmHg}$ (No-PH group; $n=56), 20<\mathrm{mPAP}<25 \mathrm{mmHg}$ (Bo-PH group; $n=18)$, and $\mathrm{mPAP} \geq 25 \mathrm{mmHg}(\mathrm{PH}$ group; $n=6)$. The demographic, hemodynamic, spirometric, and 6-min walk test (6MWT) data of the patients were collected. In addition, the 1-year incidence of AEs and 1-year survival of the patients after the initial RHC were also evaluated.
\end{abstract}

Results: There were no significant differences among the 3 groups in the mean age, pulmonary function parameters or the $\mathrm{PaO}_{2}$, however, 6-min walk distance was significantly lower in both the $\mathrm{Bo}-\mathrm{PH}$ and $\mathrm{PH}$ groups ( $p<0.001$ for both) as compared to the No-PH group. The results of the Kaplan-Meier analysis revealed that while there was no significant difference in the 1-year survival rate among the three groups, the 1-year incidence of AEs was significantly higher in both the $\mathrm{Bo}-\mathrm{PH}$ and $\mathrm{PH}$ groups ( $p<0.001, p=0.023$, respectively) as compared to the No-PH group.

Conclusions: The current study suggested that borderline $\mathrm{PH}$ may be associated with poorer exercise tolerance and an increased risk of AEs in patients with ILD. Therefore, the physicians should pay close attention to the presence of even mild elevation of the MPAP at the initial evaluation in patients with ILD.

Keywords: Acute exacerbation, Borderline pulmonary hypertension, Interstitial lung disease, Pulmonary hypertension, 6-min walk test

\footnotetext{
* Correspondence: nemoken1124@yahoo.co.jp

Department of Respiratory Medicine, National Hospital Organization,

Ibarakihigashi National Hospital, 825, Terunuma. Tokai-mura, Naka-gun,

Ibaraki 319-1113, Japan
}

(c) The Author(s). 2019 Open Access This article is distributed under the terms of the Creative Commons Attribution 4.0 International License (http://creativecommons.org/licenses/by/4.0/), which permits unrestricted use, distribution, and reproduction in any medium, provided you give appropriate credit to the original author(s) and the source, provide a link to the Creative Commons license, and indicate if changes were made. The Creative Commons Public Domain Dedication waiver (http://creativecommons.org/publicdomain/zero/1.0/) applies to the data made available in this article, unless otherwise stated. 


\section{Background}

According to the definition based on the 5th World Symposium on Pulmonary Hypertension (WSPH), patients with a resting mean pulmonary artery pressure (mPAP), as assessed by right heart catheterization (RHC), of $\geq 25 \mathrm{mmHg}$ are defined as having "pulmonary hypertension (PH)," and those with a mPAP of $\leq 20 \mathrm{mmHg}$ are defined as having "normal pulmonary hemodynamics" [1]. On the other hand, even though a precise classification and management of such patients remained unclear, patients with a mPAP in the range of 21 to $24 \mathrm{mmHg}$ were defined as having "borderline $\mathrm{PH}$ " [1]. However, recently, the 6th WSPH was held in Nice, and this task force recommended that the following definition of precapillary $\mathrm{PH}$ : concurrent presence of a mPAP of $>20$ $\mathrm{mmHg}$, pulmonary arterial wedge pressure (PAWP) of $\leq 15 \mathrm{mmHg}$, and pulmonary vascular resistance (PVR) of $\leq 3 \mathrm{WU}$ [2]. Therefore, it is speculated that the clinical evaluation of patients with even mildly elevated mPAP would be more important.

$\mathrm{PH}$ is often observed as a complication in patients with interstitial lung disease (ILD), including idiopathic pulmonary fibrosis (IPF), combined pulmonary fibrosis and emphysema (CPFE), and connective tissue disease associated with ILD (CTD-ILD) [3-9]. In patients with IPF, $\mathrm{PH}$ is an important complication, since the presence of $\mathrm{PH}$ has been shown to be associated with increased dyspnea, deterioration of gas exchange, rapid desaturation on exercise, limitation of exercise capacity as measured by the 6-min walk test (6MWT), increased risk of acute exacerbation (AE), and reduced survival [3-5, 10, 11]. $\mathrm{PH}$ is also known to be associated with an increased risk of death in patients with such ILDs as CPFE and CTDILD [6-9].

These previous studies related to $\mathrm{PH}$ in ILD serve as the basis for defining the cutoff point of the mPAP, as assessed by RHC for defining PH (mPAP $\geq 25 \mathrm{mmHg}$ ). Although some studies have reported poor outcomes in IPF patients with $\mathrm{PH}$ defined using other cutoff values (mPAP > $17 \mathrm{mmHg}$, > $20 \mathrm{mmHg}$ ) [12, 13], little is known about the clinical significance of borderline PH in ILD. Therefore, the aim of this study was to evaluate whether borderline $\mathrm{PH}$ has an impact on the exercise capacity, risk of AEs, and mortality in patients with ILD.

\section{Methods}

\section{Subjects}

We conducted a retrospective review of consecutive patients with ILD who underwent RHC between November 2013 and October 2016. RHC was performed in subjects with suspected $\mathrm{PH}$ based on clinical criteria. The diagnosis of ILD was made based on the clinical findings, serologic findings, and findings of high-resolution computed tomography (HRCT). The diagnosis of IPF was established using standard criteria [14]. Although a surgical lung biopsy was not required for confirmation, in some patients, the diagnosis was established by lung biopsy. We included all patients with CTD-ILD who were diagnosed on the basis of each criteria, however, in whom CTD-associated pulmonary arterial hypertension was excluded based on clinical judgment/multidisciplinary discussion. The exclusion criteria were as follows: (1) patients in whom the initial evaluation was performed using supplemental oxygen; (2) patients suffering from left heart disease, pulmonary arterial thromboembolism, chronic liver disease and obstructive sleep apnea syndrome, all of which could cause secondary PH other than CTD-ILD; (3) PAWP > $15 \mathrm{mmHg}$ on RHC; (4) patients with orthopedic impairment(s) that could interfere with the performance in the 6MWT. According to a previous definition based on the 5th WSPH [1], ILD patients were divided into 3 groups according to the $\mathrm{mPAP}$ as measured by $\mathrm{RHC}$ : mPAP $\leq 20 \mathrm{mmHg}$ (No-PH group), $20<$ mPAP $<25$ $\mathrm{mmHg}$ (Bo-PH group), and mPAP $\geq 25 \mathrm{mmHg}$ (PH group). This study was reviewed and approved by the Ibarakihigashi National Hospital Institutional Review Board (IRB number 2017-022).

\section{Measurements}

We recorded the patients' characteristics, pulmonary function parameters, $\mathrm{KL}-6, \mathrm{PaO}_{2}$, the results of the $6 \mathrm{MWT}$, echocardiography and hemodynamics retrospectively. All the patients underwent spirometry (CHESTAC-8900; Chest, Tokyo, Japan) based on the American Thoracic Society (ATS) recommendations for acceptability and reproducibility [15]. Single-breath DLco was also measured (CHESTAC-8900). The values of $\mathrm{VC}, \mathrm{FEV}_{1}$, TLC and DLco were expressed as percentages of the predicted normal values. The 6MWT was performed in all patients, in accordance with the ATS statement [16]. $\mathrm{SpO}_{2}$ was monitored continuously with a wireless pulse oximeter during the 6MWT. If the $\mathrm{SpO}_{2}$ fell below $85 \%$, the test was stopped for safety concerns. The distance that the patients could walk in the test was recorded as the 6-min walk distance (6MWD), and the $\Delta \mathrm{SpO}_{2}$ (initial $\mathrm{SpO}_{2}$ - lowest $\mathrm{SpO}_{2}$ on $6 \mathrm{MWT}$ ) was calculated. The right ventricular systolic pressure (RVSP) obtained by echocardiography was measured in all the patients. RHC was performed at rest using a Swan-Ganz catheter inserted percutaneously via either the jugular vein or the femoral vein. Cardiac output was measured by a thermodilution method.

We also evaluated the 1-year incidence of AEs and the 1-year survival after the initial RHC. AE of IPF was defined as previously described [17]. In brief, patients had a previous diagnosis of IPF, and presented with acute worsening of dyspnea within a 1-month period and newly developed bilateral ground-glass opacities 
and/or consolidation on HRCT, with no evidence of cardiac failure or fluid overload to explain the respiratory deterioration [17]. On the other hand, there is no existing official definition of $\mathrm{AE}$ for patients with ILDs other than IPF. However, AEs in patients with ILDs other than IPF resembles the AEs noted in patients with IPF [18]; therefore, we applied the definition of AE in patients with IPF to AE in patients with any kind of ILD.

\section{Statistical analysis}

Data are expressed as means \pm standard deviation (SD) or median (interquartile range), as appropriate. Distribution of continuous measurements was evaluated using the Shapiro-Wilk test. To assess the differences among the 3 groups of patients classified as above, we performed one-way analysis of variance (ANOVA), the Kruskal-Wallis test, and the $X^{2}$ test for parametric continuous, nonparametric continuous, and categorical measurements, respectively. The differences among the groups in the 6MWD and $\Delta \mathrm{SpO}_{2}$ were evaluated using one-way ANOVA, followed by the Tukey-Kramer post hoc test. Using the Kaplan-Meier method and the logrank test, the impacts of the mPAP on the 1-year incidence of AEs and the 1-year survival were estimated. $p$ values of $<0.05$ were considered as being indicative of statistical significance. Analysis of all data was performed using SPSS version 24 for Windows (SPSS Inc., Chicago).

\section{Results}

\section{Patient characteristics}

A total of 80 ILD patients were included in our analysis, 23 of whom had IPF (Table 1). Subjects with other ILDs included patients with CTD-ILD $(n=15), \operatorname{CPFE}(n=8)$, idiopathic non-specific interstitial pneumonia $(n=8)$, chronic hypersensitivity pneumonia $(\mathrm{n}=8)$, pleuroparenchymal fibroelastosis $(n=7)$, pneumoconiosis $(n=2)$, microscopic polyangiitis-ILD ( $\mathrm{n}=1)$, and unclassifiable

Table 1 Clinical characteristics of study population at baseline

\begin{tabular}{|c|c|c|c|c|c|}
\hline Variables & Total & $\mathrm{No}-\mathrm{PH}$ & Bo-PH & $\mathrm{PH}$ & $p$-value* \\
\hline & & mPAP $\leq 20$ & $20<$ mPAP $<25$ & mPAP $\geq 25$ & \\
\hline Subjects, $N(\%)$ & 80 & 56 & 18 & 6 & - \\
\hline Mean age (years) & $71.2 \pm 10.3$ & $70.7 \pm 11.0$ & $76.7 \pm 6.46$ & $73.4 \pm 5.32$ & 0.916 \\
\hline $\mathrm{BMI}\left(\mathrm{kg} / \mathrm{m}^{2}\right)$ & $22.5 \pm 3.99$ & $21.9 \pm 3.38$ & $21.4 \pm 2.99$ & $22.7 \pm 4.11$ & 0.182 \\
\hline Smoking status, current/former/never & $6 / 40 / 34$ & $5 / 25 / 26$ & $1 / 10 / 7$ & $0 / 5 / 1$ & 0.352 \\
\hline \multicolumn{6}{|l|}{ Underlying disease } \\
\hline IPF, N (\%) & $23(28.8)$ & $17(30.3)$ & $2(11.1)$ & $4(66.7)$ & 0.030 \\
\hline CPFE, N (\%) & $8(10.0)$ & $5(8.9)$ & $2(11.1)$ & $1(16.7)$ & 0.822 \\
\hline CTD-ILD, N (\%) & $15(18.8)$ & $11(19.6)$ & $4(22.2)$ & $0(0)$ & 0.459 \\
\hline Other ILD, N (\%) & $34(42.5)$ & $23(41.1)$ & $10(55.6)$ & $1(16.7)$ & 0.230 \\
\hline $\mathrm{KL}-6(\mathrm{U} / \mathrm{ml})$ & $1030(628,1569)$ & $968(660,1448)$ & $965(420,1575)$ & $1280(909,1526)$ & 0.521 \\
\hline $\mathrm{PaO}_{2}(\mathrm{mmHg})$ & $75.4 \pm 9.2$ & $76.7 \pm 9.3$ & $73.0 \pm 9.0$ & $73.1 \pm 9.9$ & 0.117 \\
\hline VC, \% predicted (\%) & $74.6 \pm 22.9$ & $72.7 \pm 22.5$ & $67.9 \pm 23.8$ & $79.3 \pm 19.0$ & 0.436 \\
\hline $\mathrm{FEV}_{1}, \%$ predicted (\%) & $90.3 \pm 25.3$ & $87.8 \pm 26.1$ & $84.5 \pm 18.1$ & $93.5 \pm 24.5$ & 0.637 \\
\hline TLC, \% predicted (\%) & $76.9 \pm 17.7$ & $76.0 \pm 16.2$ & $74.3 \pm 21.2$ & $78.6 \pm 14.4$ & 0.966 \\
\hline DLco, \% predicted (\%) & $50.5 \pm 22.6$ & $52.5 \pm 24.2$ & $48.2 \pm 24.3$ & $41.3 \pm 22.6$ & 0.530 \\
\hline 6MWD (m) & $342.0 \pm 130.1$ & $383.8 \pm 101.6$ & $235.2 \pm 95.3$ & $169.2 \pm 140.0$ & $<0.0001$ \\
\hline$\Delta \mathrm{SpO}_{2}(\%)$ & $7.60 \pm 4.06$ & $7.31 \pm 4.00$ & $10.0 \pm 4.14$ & $9.80 \pm 2.28$ & 0.024 \\
\hline RVSP (mmHg) & $30(24,35)$ & $28(22.5,33)$ & $33(30,38)$ & $48.5(38.8,52.3)$ & $<0.0001$ \\
\hline $\mathrm{mPAP}(\mathrm{mmHg})$ & $16.5(14,21)$ & $15(13,17)$ & $21(21,22)$ & $27.5(25.5,28.8)$ & $<0.0001$ \\
\hline PVR (dynes sec $\mathrm{cm}^{-5}$ ) & $195(152,287)$ & $180(145,210)$ & $281(211,317)$ & $378(320,494)$ & $<0.0001$ \\
\hline Cardiac index $\left(1 / \mathrm{min} / \mathrm{m}^{2}\right)$ & $2.54(2.27,2.76)$ & $2.51(2.21,2.71)$ & $2.71(2.54,3.01)$ & $2.64(2.17,2.74)$ & 0.035 \\
\hline PAWP (mmHg) & $6.23 \pm 2.68$ & $5.93 \pm 2.62$ & $7.46 \pm 2.96$ & $4.60 \pm 1.82$ & 0.056 \\
\hline
\end{tabular}

Data are presented as mean \pm standard deviation or median (interquartile range). ${ }^{*} \mathrm{p}$-value is comparison among the three groups (No- $\mathrm{PH}$, Bo- $\mathrm{PH}$, and $\mathrm{PH}$ groups). Definition of abbreviations: $\mathrm{PH}$, pulmonary hypertension; BMI, body mass index; IPF, idiopathic pulmonary fibrosis; CPFE, combined pulmonary fibrosis and emphysema; ILD, interstitial lung disease; CTD-ILD, connective tissue disease associated with ILD; KL-6, krebsvon den lungen-6; PaO2, partial pressure of oxygen; VC, vital capacity; FEV1, forced expiratory volume in $1 \mathrm{~s} ; \mathrm{TLC}$, total lung capacity; DLco, diffusing capacity for carbon monoxide; 6MWD, 6-min walk distance; SpO2, oxygen saturation as measured by pulse oximeter; $\triangle \mathrm{SpO}$, initial SpO2-lowest SpO2on 6-min walk test; RVSP, right ventricular systolic pressure; mPAP, mean pulmonary artery pressure; PVR, pulmonary vascular resistance; PAWP, pulmonary arterial wedge pressure 
ILD $(n=8)$. The numbers of CTD-ILD patients with polymyositis/dermatomyositis (PM/DM), systemic sclerosis (SSc), rheumatoid arthritis (RA) and Sjögren's syndrome (SjS) were 5 (33.3\%), 4 (26.7\%), 3 (20.0\%) and 3 (20.0\%), respectively.

The mPAP values as assessed by RHC in the 80 patients with ILD were as follows: mPAP $\leq 20 \mathrm{mmHg}$ (No-PH group; 56 patients (70\%)); $20<$ mPAP $<25$ $\mathrm{mmHg}$ (Bo-PH group; 18 patients (22.5\%)), and mPAP $\geq 25 \mathrm{mmHg}$ (PH group; 6 patients $(7.5 \%)$ ). None of the patients were receiving corticosteroids, immunosuppressive agents or vasodilator therapy at the time of the RHC. The clinical characteristics of each groups classified according to the mPAP are summarized in Table 1. There were no differences among the 3 groups in the age, BMI, smoking status, distribution of underlying diseases other than IPF, KL-6, $\mathrm{PaO}_{2}$, or measures of pulmonary function. On the other hand, the 6MWD, $\triangle \mathrm{SpO}_{2}, \mathrm{RVSP}, \mathrm{mPAP}, \mathrm{PVR}$ and cardiac index were significantly different among the 3 groups. During the follow-up period after initial evaluation on room air, only 2 patients (Bo-PH group, $n=1$; $\mathrm{PH}$ group, $\mathrm{n}=1$ ) received vasodilator therapy (tadalafil alone); 18 patients (No-PH group, $n=14$; Bo- $\mathrm{PH}$ group, $n=2$; $\mathrm{PH}$ group, $\mathrm{n}=2$ ) received anti-fibrotic drugs for IPF and 19 patients (NoPH group, $n=10$; Bo- $\mathrm{PH}$ group, $n=8$; $\mathrm{PH}$ group, $\mathrm{n}=1$ ) received corticosteroid and/or immunosuppressive therapy; 5 patients (belonging only to the $\mathrm{PH}$ group) received long-term oxygen therapy.

\section{Association between mPAP and 6MWD}

Comparisons of the $6 \mathrm{MWD}$ and $\triangle \mathrm{SpO}_{2}$ among the three groups are shown in Fig. 1. The 6MWD was significantly lower in both the Bo-PH and $\mathrm{PH}$ groups than in the No$\mathrm{PH}$ group $(p<0.001$ for both), however, there was no difference between the Bo- $\mathrm{PH}$ group and $\mathrm{PH}$ group. Although there were no significant differences in the $\Delta \mathrm{SpO}_{2}$ among the groups, the $\Delta \mathrm{SpO}_{2}$ was higher in the Bo-PH group as compared to the No-PH group ( $p=$ 0.059).

\section{Association between the MPAP and the 1-year incidence of $A E$ and 1-year survival}

Kaplan-Meier analysis showed that the 1-year incidence of $\mathrm{AE}$ was significantly higher in both the $\mathrm{Bo}-\mathrm{PH}$ and $\mathrm{PH}$ groups as compared to the No-PH group ( $\mathrm{p}<0.001$, $p=0.023$, respectively) (Fig. 2). In contrast, the KaplanMeier analysis revealed no significant differences in the 1 -year survival among the 3 groups (Fig. 3 ).

\section{Discussion}

The current study shows that not only $\mathrm{PH}$, but also borderline $\mathrm{PH}$, is associated with a decreased exercise capacity and increased risk of AEs in patients with ILD. Therefore, in ILD patients, presence of borderline PH, as defined by a mPAP in the range of 21 to $24 \mathrm{mmHg}$, should be recognized as a clinical importance similar to $\mathrm{PH}$.

$\mathrm{PH}$ is a common complication in patients with ILD [2-8]. Lettieri et al. reported that the prevalence of $\mathrm{PH}$ was high $(31.6 \%)$ in patients with advanced IPF who were referred for lung transplantation [3]. On the other hand, in two different reports of initial evaluation studies which included IPF patients with milder pulmonary function impairment, PH were reported in 8.1 and 14.9\% of patients, respectively $[12,13]$. In this study, conducted in ILD patients in whom RHC had been performed at the time of the initial evaluation, we found a similar prevalence of $\mathrm{PH}$ (13\%, 6 of 80 patients) to that in the aforementioned studies.
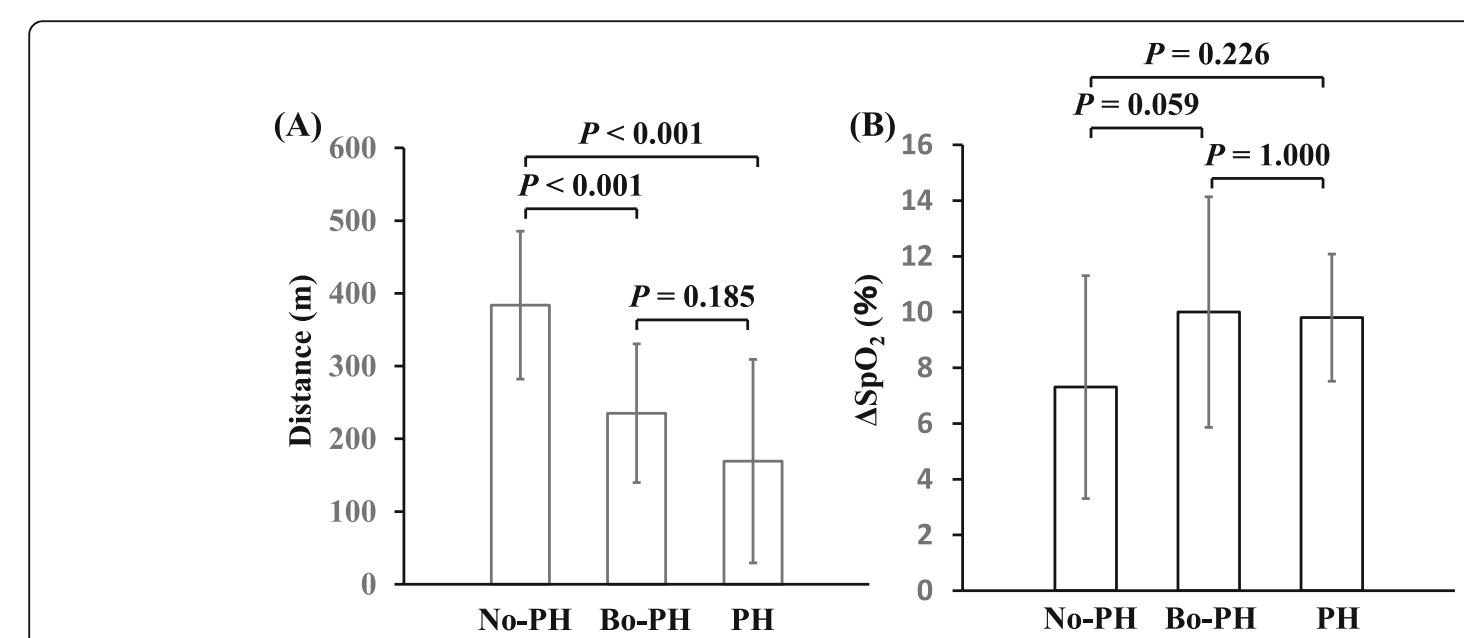

Fig. 1 Mean walking distance $(\mathrm{m})$ in the $6 \mathrm{MWT}$ (a) and $\Delta \mathrm{SpO}_{2}$ (\%) defined by initial $\mathrm{SpO}_{2}-$ lowest $\mathrm{SpO}_{2}$ on $6 \mathrm{MWT}$ (b) in the 3 groups of ILD patients. Definition of abbreviations: $6 \mathrm{MWT}$, 6-min walking test; $\mathrm{SpO}_{2}$, oxygen saturation as measured by pulse oximeter; $\mathrm{PH}$, pulmonary hypertension 


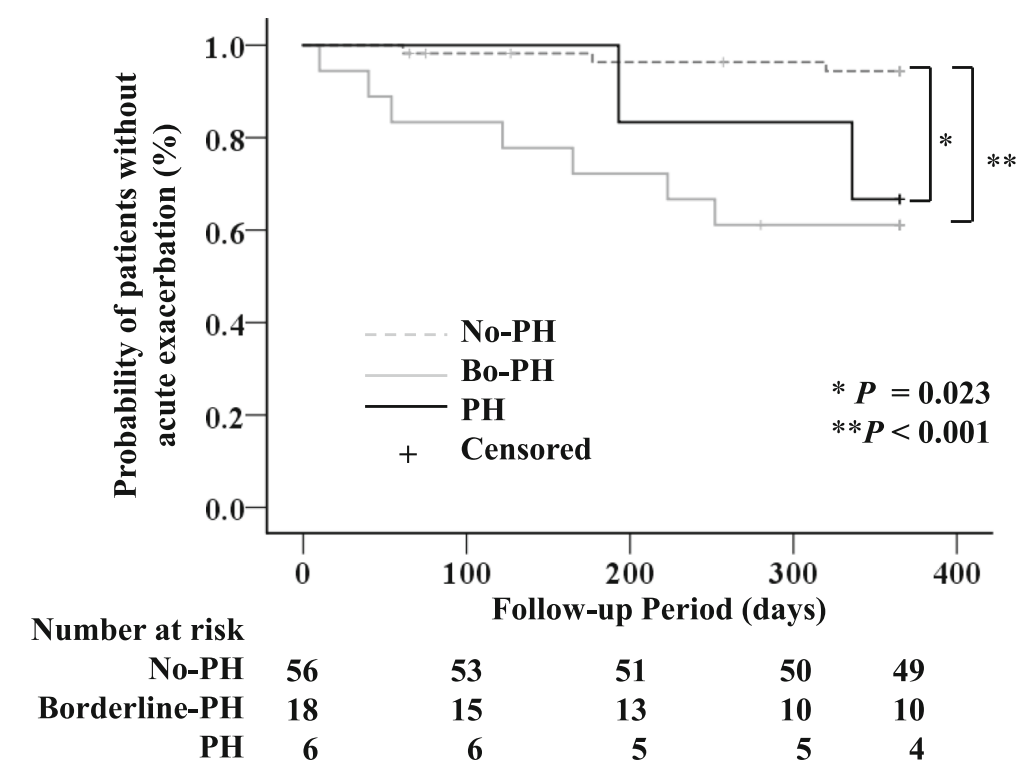

Fig. 2 Kaplan-Meier analysis for the onset of acute exacerbation of ILD according to the 3-groups of ILD patients. *Significant difference between No-PH and PH: $p=0.023$. * Significant difference between No-PH and Bo-PH: $p<0.001$. Definition of abbreviations: ILD, interstitial lung disease; $\mathrm{PH}$, pulmonary hypertension

In regard to the definition of $\mathrm{PH}$, there are only a limited number of studies that have reported the clinical significance of mPAP in the region of the lower cutoff value in patients with ILD. Hamada et al. demonstrated the influence of elevated mPAP $(>17 \mathrm{mmHg}$ ) on the prognosis of IPF [12]. Kimura et al. and Suzuki et al. showed that higher values of the mPAP $(>20 \mathrm{mmHg}$ ) at the initial evaluation were associated with an increased risk of death in patients with IPF and lung-dominant connective tissue disease, respectively $[13,19]$. In addition, Kimura et al. showed that the prognosis seemed to be almost the same between IPF patients with mPAP values in the range of $21-25 \mathrm{mmHg}$ and those with $\mathrm{mPAP}>25 \mathrm{mmHg}$ [13]. These studies suggested that a lower cutoff point may be better for defining PH, however, they provided insufficient data to determine

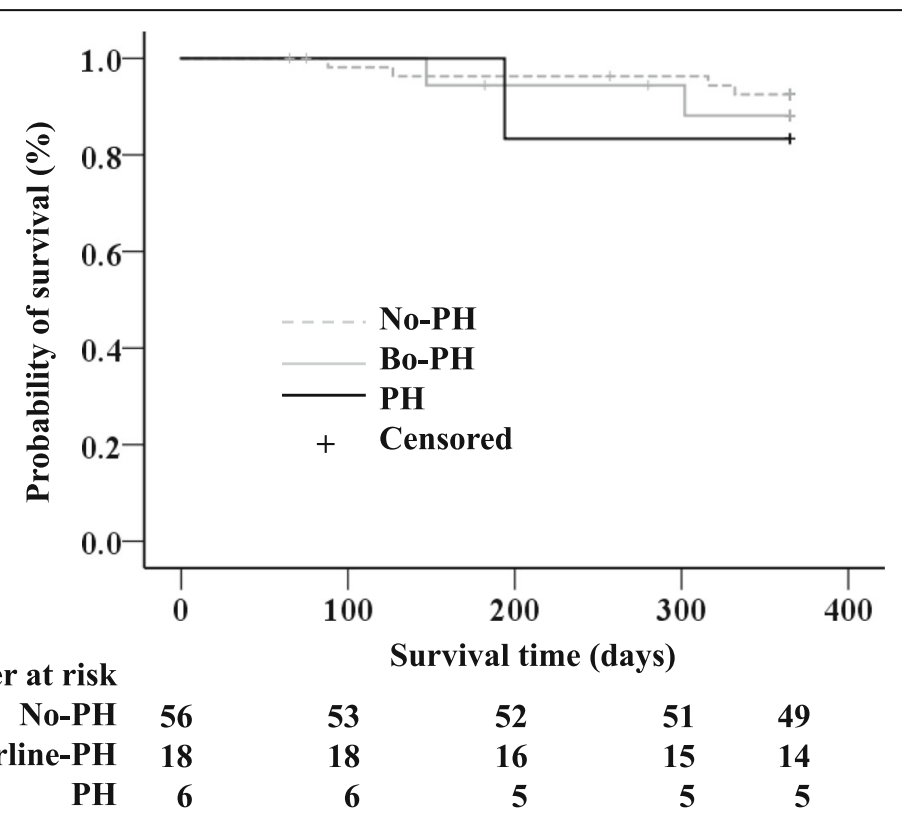

Fig. 3 Kaplan-Meier analysis for the 1-year survival according to the 3-groups of ILD patients. There were no significant differences among the 3 groups. Definition of abbreviations: ILD, interstitial lung disease; PH, pulmonary hypertension 
the clinical importance of borderline $\mathrm{PH}$ in patients with ILD.

Previous studies have documented that, relative to the measures of pulmonary function and hypoxia, altered pulmonary hemodynamics had a greater impact on the $6 \mathrm{MWD}$ in patients with IPF $[3,4]$. In fact, several studies have shown that the 6MWD was significantly shorter in IPF patients with $\mathrm{PH}$ than in IPF patients without $\mathrm{PH}[3,4,11]$. In this study, ILD patients with $\mathrm{PH}$ had a shorter 6MWD than those with normal pulmonary hemodynamics, consistent with previous reports $[3,4,11]$. Our results also showed that the 6MWD was shorter in the Bo-PH group than that in the No- $\mathrm{PH}$ group. These results suggest that not only the presence of $\mathrm{PH}$, but also that of borderline $\mathrm{PH}$, had a significant implication for exercise intolerance in patients with ILD. However, there was no difference in the 6MWD between the Bo-PH group and $\mathrm{PH}$ group in this study. In general, higher mPAP was associated with more significant exercise intolerance in patients with IPF [11]. This result could be related to the small sample size and absence of cases with sever disease in our $\mathrm{PH}$ group.

In this study, although both the $\mathrm{Bo}-\mathrm{PH}$ and $\mathrm{PH}$ groups seemed to have higher $\Delta \mathrm{SpO}_{2}$ values (initial $\mathrm{SpO}_{2}-$ lowest $\mathrm{SpO}_{2}$ on $6 \mathrm{MWT}$ ) as compared to the No-PH group, there were no significant differences among the 3 groups. These results are in contrast to the previous report that the lowest $\mathrm{SpO} 2$ during the $6 \mathrm{MWT}$ was significantly lower in IPF patients as compared to that in patients without $\mathrm{PH}$ [3]. This discrepancy may be explained by the difference in the 6MWT, which was performed under the local rule that it was stopped, owing to safety concerns, if the $\mathrm{SpO}_{2}$ fell below $85 \%$. In this study, there were $9 / 56(16 \%)$ in the No- $\mathrm{PH}$ group, $8 / 18(44 \%)$ in the Bo-PH group, and 5/6 (83\%) in the $\mathrm{PH}$ group in whom this rule was applied. Therefore, the $\Delta \mathrm{SpO}_{2}$ in both the Bo-PH and $\mathrm{PH}$ groups in our study may have been underestimated as compared to that in the No-PH group.

In this study, among the 80 patients who underwent RHC during their initial workup, the 1-year incidence of $\mathrm{AE}$ after $\mathrm{RHC}$ was $21.3 \%$ (17 patients). On the other hand, Song et al. reported that the 1-year incidence of $\mathrm{AE}$ was $14.2 \%$ in a retrospective review of 461 patients with IPF [20]. However, this study included subjects with milder pulmonary function impairment (mean \%FVC > $72 \%$, mean \% TLC $>73.8 \%$, mean \%DLco $>62.2 \%$ ) than those in our study, and the presence of $\mathrm{PH}$ at the baseline was not evaluated [20]. Therefore, it is possible that the higher incidence of $\mathrm{AE}$ in our study might be due to fact that our patients had a relatively greater severity of ILD when they underwent the initial workup.

Our study revealed that the presence of $\mathrm{PH}$ at the baseline was associated with an increased risk of AEs in patients with ILD. This result was consistent with those reported by Judge, who showed that $\mathrm{PH}$ was an independent predictor of the development of AEs in patients with advanced IPF [10]. There are insufficient data about the mechanism by which $\mathrm{PH}$ increases the risk of AEs in patients with ILD. Previous reports have shown that the pathogenetic mechanisms of $\mathrm{PH}$ in cases of IPF include hypoxic vasoconstriction, destruction of the pulmonary capillaries, and vascular remodeling mediated by various growth factors, such as vascular endothelial growth factor, platelet-derived growth factor and transforming growth factor- $\beta[4,5,21]$. Although the etiology of AE remains uncertain, Collard et al. suggested that the pathobiology of $\mathrm{AE}$ in patients with IPF involves both acceleration of the underlying chronic factors contributing to the fibrotic process and acute factors that lead to widespread acute lung injury [17]. Various growth factors which are related to the development of $\mathrm{PH}$ are also likely intrinsic factors that cause progression of the underlying fibrotic condition; therefore, the presence of $\mathrm{PH}$ might have increased the risk of $\mathrm{AE}$ in this study. We also showed that the 1year incidence of AEs was significantly higher in the Bo$\mathrm{PH}$ group than in the No-PH group. Therefore, these results seem to confirm that the presence of a mPAP of > $20 \mathrm{mmHg}$ was redefined as an initial pulmonary vasculopathy in patients with ILD [2].

In our study, there were no differences in the 1-year survival among the 3 groups. This result was in contrast to previous reports $[3,13]$. Lettieri et al. reported that the 1-year mortality rate was significantly greater in IPF patients with $\mathrm{PH}$ who were listed for lung transplantation as compared to those without $\mathrm{PH}$ [3]. Kimura et al. divided the IPF patients undergoing $\mathrm{RHC}$ into 3 groups (mPAP $\leq 20 \mathrm{mmHg}, 21-25 \mathrm{mmHg}$, and $>25$ $\mathrm{mmHg}$ ) and compared the 5-year survival according to the mPAP [13]. In their study, significant differences in the mortality were demonstrated among the 3 groups, and patients with mPAP in the range of $21-25 \mathrm{mmHg}$ and $>25 \mathrm{mmHg}$ had higher mortality rates [13]. This discrepancy may be explained by differences in the underlying diseases, sample size, and follow-up period. Furthermore, in this study, the treatment decision after the initial work-up was left to the discretion of the treating physician and thus of limited homogeneity. Therefore, further studies will be necessary to elucidate the association between the presence of borderline $\mathrm{PH}$ and mortality in ILD patients.

Our study has several limitations. First, this is a retrospective study with small number of patients. The sample size in this study seemed to confer the low statistical power to detect significant survival indicate. While the size of our study population is limited, the fact that ILD patients with borderline $\mathrm{PH}$ had a shorter 6MWD and higher risk of AEs than those with normal pulmonary 
hemodynamics leads to a good rationale for clinical significance of borderline $\mathrm{PH}$. Second, our study included only initial evaluations performed on room air. Since the need for supplemental oxygen is common among patients with advanced ILD, the severe cases of ILD may have been excluded from this study. However, 6MWT may be influenced by supplemental oxygen therapy, because of an improvement of exercise-induced hypoxic pulmonary vasoconstriction. In fact, previous studies of the 6MWT have also excluded individuals using supplemental oxygen therapy $[3,13]$.

\section{Conclusions}

The current findings suggest that in ILD patients, the presence of borderline $\mathrm{PH}$, as defined by a mPAP in the range of 21 to $24 \mathrm{mmHg}$, may be associated with poorer exercise tolerance and an increased risk of AEs, similar to the presence of $\mathrm{PH}$. Therefore, it is recommended that physicians should pay attention to even mild elevation of the mPAP at the initial evaluation in patients with ILD.

\begin{abstract}
Abbreviations
6MWD: 6-min walk distance; 6MWT: 6-min walk test; AE: Acute exacerbation; ATS: American Thoracic Society; CPFE: Combined pulmonary fibrosis and emphysema; CTD-ILD: Connective tissue disease associated with ILD; DLco: Diffusing capacity for carbon monoxide; $\mathrm{FEV}_{1}$ : Forced expiratory volume in $1 \mathrm{~s}$; HRCT: High-resolution computed tomography; ILD: Interstitial lung disease; IPF: Idiopathic pulmonary fibrosis; KL-6: Krebs von den lungen6; mPAP: Mean pulmonary artery pressure; $\mathrm{PaO}_{2}$ : Partial pressure of oxygen; PAWP: Pulmonary arterial wedge pressure; PH: Pulmonary hypertension; PM/ DM: Polymyositis/dermatomyositis; PVR: Pulmonary vascular resistance; RA: Rheumatoid arthritis; RHC: Right heart catheterization; RVSP: Right ventricular systolic pressure; SD: Standard deviation; SjS: Sjögren's syndrome; $\mathrm{SpO}_{2}$ : Oxygen saturation as measured by pulse oximeter; SSc: Systemic sclerosis; TLC: Total lung capacity; VC: Vital capacity; WSPH: World Symposium on Pulmonary Hypertension
\end{abstract}

\section{Acknowledgements}

The authors thank Dr. Yasuhiro Umezu for providing valuable technical support.

\section{Authors' contributions}

$\mathrm{KN}, \mathrm{TA}, \mathrm{YY}, \mathrm{HG}, \mathrm{MN}, \mathrm{YS}, \mathrm{HT}, \mathrm{NA}, \mathrm{HI}, \mathrm{KH}, \mathrm{HH}, \mathrm{YM}, \mathrm{TT}$ : Collected and analyzed data. KN, SO: Reviewed the data and wrote the manuscript. KN, SO, IH, KH, TS: Contributed to data analysis and manuscript writing. All authors read and approved the final manuscript.

\section{Funding}

This study has received no funding.

\section{Availability of data and materials}

The datasets used and/or analysed during the current study are available from the corresponding author on reasonable request.

\section{Ethics approval and consent to participate}

This retrospective study was approved by the Ibarakihigashi National Hospital Institutional Review Board (IRB number 2017-022). The need for informed consent was waived.

\section{Consent for publication}

Not applicable.

\section{Competing interests}

The all authors declare that they have no competing interests.
Received: 17 June 2019 Accepted: 28 August 2019

Published online: 02 September 2019

\section{References}

1. Hoeper MM, Bogaard HJ, Condliffe R, Frantz R, Khanna D, Kurzyna M, et al. Definitions and diagnosis of pulmonary hypertension. J Am Coll Cardiol. 2013;62:D42-50

2. Simonneau G, Montani D, Celermajer DS, Denton CP, Gatzoulis MA, Krowka M, et al. Haemodynamic definitions and updated clinical classification of pulmonary hypertension. Eur Respir J. 2019;53:1801913.

3. Lettieri CJ, Nathan SD, Barnett SD, Ahmad S, Shorr AF. Prevalence and outcomes of pulmonary arterial hypertension in advanced idiopathic pulmonary fibrosis. Chest. 2006;129:746-52.

4. Patel NM, Lederer DJ, Borczuk AC, Kawut SM. Pulmonary hypertension in idiopathic pulmonary fibrosis. Chest. 2007:132:998-1006.

5. Nathan SD, Noble PW, Tuder RM. Idiopathic pulmonary fibrosis and pulmonary hypertension. Am J Respire Crit Care Med. 2007;175:875-80.

6. Cottin V, Nunes H, Brillet PY, Delaval P, Devouassoux G, Tillie-Leblond I, et al. Combined pulmonary fibrosis and emphysema: a distinct underrecognised entity. Eur Respir J. 2005;26:586-93.

7. Cottin V, Pavec JL, Prévot G, Mal H, Humbert M, Simonneau G, Cordier JF, GERM"O"P. Pulmonary hypertension in patients with combined pulmonary fibrosis and emphysema syndrome. Eur Respir J. 2010:35:105-11.

8. Takahashi K, Taniguchi H, Ando M, Sakamoto K, Kondoh Y, Watanabe N, et al. Mean pulmonary arterial pressure as a prognostic indicator in connective tissue disease associated with interstitial lung disease: a retrospective cohort study. BMC Pulm Med. 2016;16:55.

9. Seeger W, Adir Y, Barberà JA, Champion H, Coghlan JG, Cottin V, et al. Pulmonary hypertension in chronic lung disease. J Am Coll Cardiol. 2013;62: D109-16.

10. Judge EP, Fabre A, Adamali HI, Egan JJ. Acute exacerbations and pulmonary hypertension in advanced idiopathic pulmonary fibrosis. Eur Respir J. 2012; 40:93-100.

11. Minai OA, Santacruz JF, Alster JM, Budev MM, McCarthy K. Impact of pulmonary hemodynamics on 6-min walk test in idiopathic pulmonary fibrosis. Respir Med. 2012:106:1613-21.

12. Hamada K, Nagai S, Tanaka S, Handa T, Shigematsu M, Nagao T, et al. Significance of pulmonary arterial pressure and diffusion capacity of the lung as prognosticator in patients with idiopathic pulmonary fibrosis. Chest. 2007:131:650-6.

13. Kimura M, Taniguchi H, Kondoh Y, Kimura T, Kataoka K, Nishiyama O, et al. Pulmonary hypertension as a prognostic indicator at the initial evaluation in idiopathic pulmonary fibrosis. Respiration. 2013:85:456-63.

14. Raghu G, Collard HR, Egan JJ, Martinez FJ, Behr J, Brown KK, et al. An official ATS/ ERS/JRS/ALAT statement: idiopathic pulmonary fibrosis: evidence-based quidelines for diagnosis and management. Am J Respir Crit Care Med. 2011;183:788-824.

15. American Thoracic Society. Standardization of spirometry, 1994 update. Am J Respir Crit Care Med. 1995;152:1107-36.

16. ATS Committee on Proficiency Standards for Clinical Pulmonary Function Laboratories. ATS statement: guidelines for the six-minute walk test. Am J Respire Crit Care Med. 2002:166:111-7.

17. Collard HR, Ryerson CJ, Corte TJ, Jenkins G, Kondoh Y, Lederer DJ, et al. Acute exacerbation of idiopathic pulmonary fibrosis. Am J Respir Crit Care Med. 2016:194:265-75.

18. Park IN, Kim DS, Shim TS, Kin CM, Lee SD, Koh Y, et al. Acute exacerbation of interstitial pneumonia other than idiopathic pulmonary fibrosis. Chest. 2007;132:214-20.

19. Suzuki A, Taniguchi H, Watanabe N, Kondoh Y, Kimura T, Kataoka K, et al. Significance of pulmonary arterial pressure as a prognostic indicator in lungdominant connective tissue disease. PLoS One. 2014:9:e108339.

20. Song JW, Hong SB, Lim CM, Koh Y, Kim DS. Acute exacerbation of idiopathic pulmonary fibrosis: incidence, risk factors and outcome. Eur Respir J. 2011;37:356-63.

21. Farkas $L$, Gauldie J, Voelkel NF, Kolb M. Pulmonary hypertension and idiopathic pulmonary fibrosis. A tale of angiogenesis, apoptosis, and growth factors. Am J Respir Cell Mol Biol. 2011;45:1-15.

\section{Publisher's Note}

Springer Nature remains neutral with regard to jurisdictional claims in published maps and institutional affiliations. 